\title{
A comparative clinical study of the effectiveness of computer cognitive training in patients with post-stroke cognitive impairments without dementia
}

\author{
Semen V. Prokopenko, ${ }^{\mathrm{a}, \mathrm{b}}$, Anna F. Bezdenezhnykh ${ }^{\mathrm{a}, \mathrm{b}^{*}}$, \\ Elena U. Mozheyko ${ }^{\mathrm{a}, \mathrm{b}}$, Marina M. Petrova ${ }^{\mathrm{a}}$ \\ a Department of Neurology and Medical Rehabilitation, Krasnoyarsk State Medical University \\ named after professor V.F. Voyno-Yasenetsky, Krasnoyarsk, Russia \\ ${ }^{\mathrm{b}}$ Center of Neurology and Neurorehabilitation, the Federal Siberian Research Clinical Centre \\ under the Federal Medical Biological Agency of Russia, Krasnoyarsk, Russia \\ *Corresponding author: E-mail: bezdenezhnih_af@mail.ru
}

Introduction. A complex of computer neuropsychological programs was developed at KrasSMU, which in several pilot studies has shown effectiveness in cognitive training for patients with vascular cognitive impairments (VCI).

Objectives. The aim of the present study was to compare changes in cognitive status in those patients with post-stroke VCI who worked with neuropsychological computer programs, with those changes experienced by a group of similar patients who played entertaining computer games.

Methods. Patients in the early recovery period after a hemispheric stroke with VCI without dementia ( $\mathrm{N}=26$, age 40-67) were randomized into three groups. All patients underwent conventional treatment in a rehabilitation hospital. Patients in the intervention group had ten daily 40 -minute training sessions with neuropsychological computer programs. Participants in the active control group played entertaining computer games, and kept an identical regimen. Patients in the passive control group received only conventional treatment. Cognitive, neurological, affective, and functional states were assessed before and after the training periods.

Results. Significant improvements were observed in the intervention group as compared to the passive control group on the Montreal Cognitive Assessment (MoCA, $\mathrm{p}=0.0004)$, the Clock Drawing Test (CDT, $\mathrm{p}=0.001)$, and the Frontal Assessment Battery (FAB, $\mathrm{p}=0.01$ ). Differences between the groups of patients playing neuropsychological and entertaining games were statistically insignificant (Mann-Whitney $U$ test, $p>0.05$ ), although in the intervention group there were improvements on every cognitive scale after the training period (Wilcoxon matched pairs test, $\mathrm{p}<0.05$ ), while in the active control group, enhancements were evident only on some cognitive scales $(\mathrm{p}<0.05)$. No changes were observed in the passive control group. 
Conclusions. Neuropsychological computer programs enhance cognitive status in patients with post-stroke VCI. It is possible that entertaining computer games can also improve cognitive functions. In all groups, no changes of functional state were observed before and after the training period.

Keywords: Cognitive training, computer cognitive training, stroke, cognitive rehabilitation, neuropsychological computer programs, vascular cognitive impairments, poststroke cognitive impairments.

\section{Introduction}

Stroke is an important medical and social problem. Every year, approximately six million people suffer from stroke worldwide, of which 450,000 are located in Russia (Stakhovskaya, Klochikhina, Bogatyreva, \& Kovalenko, 2013; Klochikhina \& Stakhovskaya, 2014; Feigin, Lawes, Bennett, Barker-Collo, \& Parag, 2009; Feigin et al., 2014). According to different authors, cognitive dysfunction after stroke is observed in 20 to $90 \%$ of all cases (Gottesman \& Hillis, 2010); Pendlebury \& Rothwell, 2009). Over the last few years, more scientists have begun studying this problem, but in clinical practice, addressing post-stroke cognitive impairments has taken a back seat to dealing with motor dysfunctions (Lees, Fearon, Harrison, Broomfield, \& Quinn, 2012). Cognitive impairments decrease success in rehabilitation outcomes and disease prognosis; they cause an inability to work and to take care of one's self (Narasimhalu et al. 2011; Cumming, Brodtmann, Darby, \& Bernhardt, 2014).

There are two common therapeutic methods in use: drug treatment and cognitive rehabilitation. Recently, an increasingly promising evidence base for cognitive rehabilitation after acute brain injuries has emerged.

Cognitive rehabilitation is the best available form of treatment for people who exhibit neurocognitive impairment and functional limitations after a traumatic brain injury or stroke. At present, cognitive rehabilitation is recommended as standard practice for left visual neglect, aphasia, and apraxia in patients after stroke (Cicerone et al., 2011). Also, Xu, Ren, Prakash, Vijayadas, \& Kumar (2013) suggest that there is sufficient evidence to support the conclusion that cognitive therapies are effective treatments for attention-related and visual perceptual problems in post-stroke patients. There is little evidence to suggest that executive function interventions have the potential to improve aspects of executive functioning in adults with stroke (Poulin, Korner-Bitensky, \& Dawson, 2013). Evaluating the efficacy of different cognitive rehabilitation methods and approaches is very difficult due to differences in patients' ages, brain injuries, and cognitive dysfunctions, as well as the difficulties of conducting randomized clinical trials in this field (Hénon et al., 2001).

Computer cognitive training is one of the directions cognitive rehabilitation has taken. Computer technologies for cognitive training have been increasingly used in clinical and scientific practice since the 1980s. Since that time, computer programs have been created for the selective training of attention, memory, visual perception, planning, and problem-solving. Each of these programs contains tasks that concentrate on one cognitive domain. Nevertheless, the majority of tasks inevitably affects all spheres of mental activity simultaneously (Grigoreva, Kovyazina, \& Thostov, 2012). 
One of the advantages of computer training programs is that they allow individual patient rehabilitation at home, either independently or with caregiver assistance. Secondly, there is the potential for continuous training in several cognitive domains, for automatic level control, and for scoring. When a patient is motivated by a game, he/she is more involved in the process, which ensures his/her compliance with the rehabilitation program. It should be noted that these advantages are in addition to the lower cost of this approach.

Although the effectiveness of computer-based cognitive rehabilitation has still not been thoroughly studied, some brain game programs have shown effectiveness, according to separate studies in different groups of healthy participants and patients (Sternberg et al., 2013; Hardy, Drescher, Sarkar, Kellett, \& Scanlon, 2011; Finn \& McDonald, 2011; Karen et al., 2013). Up until now, the generalization of these improvements from the games to activities of the patient's daily life has not been proven (Van de Ven, Murre, Veltman, \& Schmand, 2016; Zucchella, Capone et al, 2014).

The Department of Neurology and Medical Rehabilitation of the Krasnoyarsk State Medical University was the first to develop a Russian computer complex of neuropsychological programs for cognitive rehabilitation. This complex has proven effective in the correction of post-stroke cognitive impairments in acute and early recovery periods in some previous studies (Prokopenko et al., 2013; Prokopenko et al., 2012). The aim of the present study is to reveal the benefits of special computer-based cognitive rehabilitation. First, a neuropsychological assessment of the post-stroke patients in the intervention group and control groups before and after the rehabilitation course was conducted. Then, the results of cognitive training with the authors' computer programs for post-stroke patients were compared with the cognitive status in a similar group of patients who played entertaining games, and in a control group, where participants received only conventional treatment.

\section{Materials and Methods}

\section{Participants}

This study was conducted in the Siberian Clinical Center of the Federal Medical and Biological Agency of Russia in Krasnoyarsk city. Twenty-five participants who received conventional treatment in the Neurorehabilitation Center were randomized into three groups. The intervention group consisted of ten individuals (six males and four females) median age 59.5 [57;60]. Patients in the intervention group were treated using the authors' computer neuropsychological programs. Patients in the active control group played entertaining computer games (six participants: four males and two females, median age $58[49 ; 61]$ ). Nine individuals from the passive control group received physiotherapy only (eight males and one female, median age $62.55[61 ; 65])$. A simple randomization using simple random tables was performed.

Patients aged 40-67, with vascular cognitive impairments without dementia in early recovery periods of ischemic hemispheric stroke (up to six months after 
stroke), were included. According to ICD-10, their clinical diagnoses were coded I63.3, I63.4, and I63.5.

Exclusion criteria were: decompensation of somatic and neurologic diseases; epilepsy; severe cognitive dysfunction; severe and moderate aphasia; and severe decrease of vision or hearing.

\section{Diagnostic methods}

In the first days after admission, the patients were examined by a neurologist in order to provide a clinical diagnosis; by a physician in order to assess concomitant somatic pathology; and by a speech therapist in order to exclude moderate and severe aphasia. Clinical diagnosis of hemispheric stroke was confirmed using neuroimaging (computer-aided tomography or magnetic resonance imaging). Electroencephalography was provided to exclude seizure patterns.

The National Institutes of Health Stroke Scale (NIHSS) was added to the neurological examination. Patients scored from one to thirteen points on the NIHSS. The neuropsychological examination consisted of a number of valid cognitive scales: the Mini Mental State Examination (MMSE), Frontal Assessment Battery (FAB), Montreal Cognitive Assessment (MoCA), Clock Drawing Test (CDT), and Shulte's test. Included were patients who scored 20-28 points on the MMSE, 5-16 points on the FAB, 17-24 on the MoCA, and 35 to 150 seconds on Shulte's test. Additional assessment of visual and spatial gnosis was made through the Clock Drawing Test. The patients scored from five to ten points.

Each patient's functional state was estimated using a modified version of the Instrumental Activity of Daily Living Scale. The Hospital Anxiety and Depression Scale (HADS) was used to evaluate affective status. Patients were considered to have subclinical anxiety or depression if they scored seven points or more. If they scored eleven points or more, they were considered as having a clinical level of depression and/or anxiety. Study participants scored $0-18$ points on the anxiety subscale, and 1-13 points on the depression subscale.

An evaluation of the patients' neurological, cognitive, affective, and functional states using these scales was performed before and after the observational period (the first examination during the first/second days on admission, and the second examination on the day after the last day of training). After the treatment course, there was also an evaluation of the subjective global impressions of both the patients and clinicians, using the CGIS (Clinician's Global Impression Scale) and PGIS (Patient's Global Impression Scale).

The study protocol was approved by the Local Ethics Committee of Krasnoyarsk State Medical University. All participants signed informed consent forms.

\section{Treatment methods}

Participants in all groups had a complex course of physiotherapy and drug treatment in the Neurorehabilitation Center. Then, patients in the intervention group were trained using the original complex of neuropsychological programs developed at Krasnoyarsk State Medical University (KrasSMU). They had ten daily training 
sessions of 30-40 minutes' duration. During the first few sessions, an instructor demonstrated how to use a computer and explained the tasks and rules for each training program. Later, participants could train independently, but they remained under the supervision of the instructor. Levels of complexity could be increased depending on patients' abilities.

Participants in the active control group, apart from receiving physiotherapy and drug treatment, played entertaining computer games according to an identical regimen. Entertaining arcade and arkanoid games were used. These games are quite simple, but they simultaneously stimulate attention and increase reaction time.

Patients in the passive control group had physiotherapy and drug treatment without any cognitive rehabilitation during a ten-day observation period.

In all groups, drug therapy included antihypertensive, disaggregant, anticoagulant, and hypolipidemic agents for secondary stroke prevention. Also, all participants, independent of the group in which they were included, were prescribed one of the following neurometabolic or antioxidant drugs: choline alfoscerate, ethylmethylhydroxypyridine succinate, pentoxyphyllinum, magnesii sulfas, cytoflavin, or piracetam. Some patients received antispastic, hypoglycemic, and other medications. Hence, every participant received an individual complex drug therapy.

\section{Computer complex of neuropsychological correction}

The KrasSMU complex of neuropsychological programs for cognitive correction is based on the classical neuropsychological approach of Alexander Luria. It consists of various computer program modules that are focused on training different cognitive functions such as memory, attention, counting etc. The software is available on CD, and patients also can avail themselves of rehabilitation on-line. Some of the neuropsychological programs used are described below.

Training of visual and spatial gnosis using the computer-based "Figure-Background" test. A visual and spatial training program was developed as a computer-based version of the "Figure-Background" test, with a feedback mode and a gradually decreasing intensity of background noise. A picture with a decreasing intensity of background noise is presented on a computer screen. There are several different pictures without a background in the top part of the screen. One of these pictures corresponds to the image presented in the task with the noise; other pictures represent various images of objects and letters.

During the training session, a patient is asked to identify the image in the picture with noise, and click on the corresponding image in the top part of the screen. There is then a gradual reduction of noise intensity, up to its complete disappearance. The patient needs to recognize the image as soon as possible. The speed of recognition is assessed on a scale of $0-10$. The accuracy of performance is marked by applause or a signal "incorrect" (Figure 1).

Visual and spatial memory training using pattern position-test. The training of visual and spatial memory is aimed at getting the patient to remember the position of images, with a gradually increasing number of objects (images of books, berries, etc.) in cells of a square. After presentation of various pictures arranged in cells, the pic- 


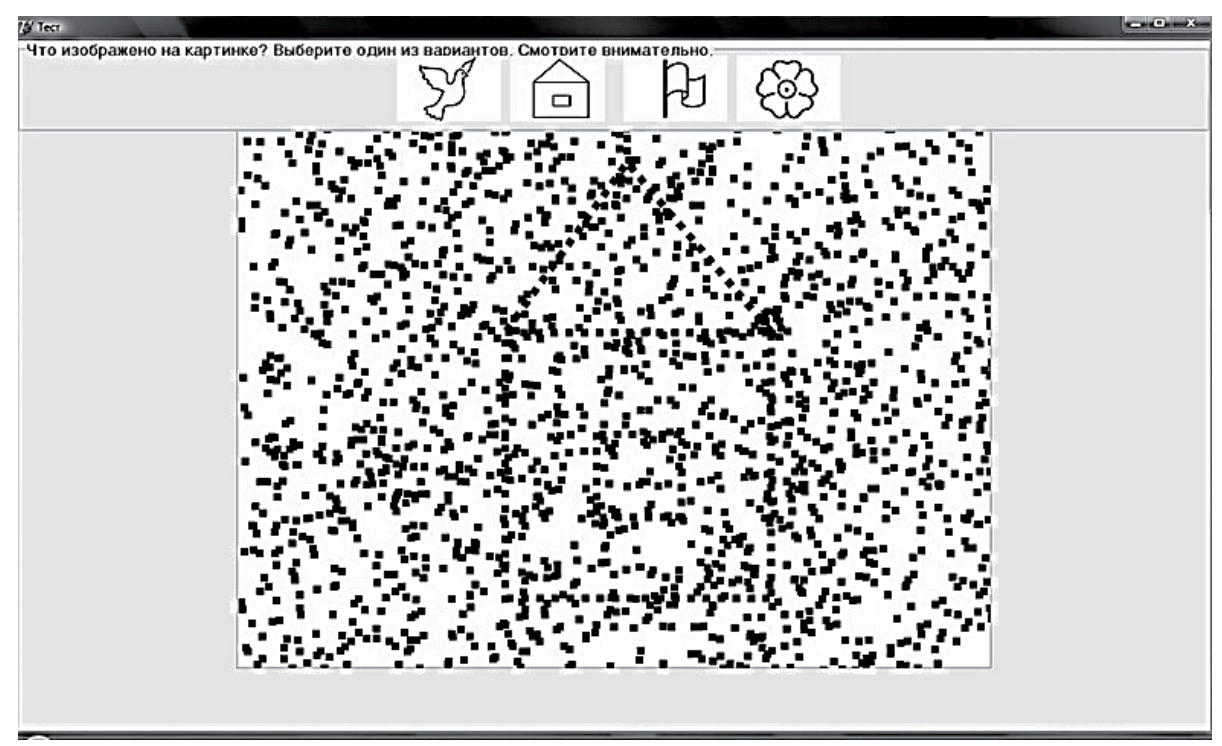

Figure 1. Computer program for training visual and spatial gnosis using background-noised images

tures are hidden, and then the patient is asked to click on the cells where pictures he or she remembers were located. After a correct performance, the number of objects for memorization is increased by one. Training continues until the patient makes two mistakes, and is followed by the appearance of information about the speed and correctness of answers, and the highest volume of information memorized on a screen (Figure 2). Then, the participant goes up to the next level, where the quantity of cells increases.

The neuropsychological program complex for cognitive rehabilitation also included a program for training visual memory, using tasks for the memorization of sequences of nonverbal patterns; a program for training spatial gnosis arranging clock hands; a program for impetuosity correction; a program for speed counting; and a program for attention training using a computer-based Shulte's tables test.

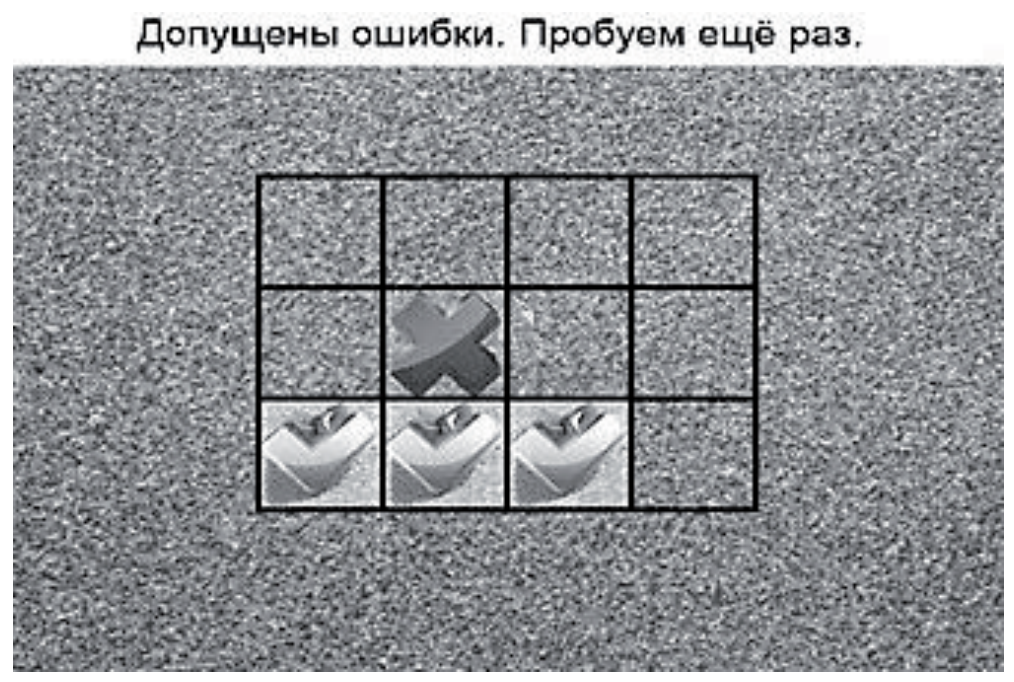

Figure 2. The program for training visual and spatial memory. Level 1 


\section{Statistical analysis}

Data analysis was conducted using a software application package called "Statistica 7." Due to the small sample sizes, parametric statistical methods could not be used. All data were described as Median and the first and the third quantiles (Me [Q1;Q3]), and the data were analyzed using nonparametric statistics. The KruskalWallis test ( $p>0.05)$ was conducted to compare groups before the intervention. The Wilcoxon Matched Pairs Test $(\mathrm{p}<0.05)$ was used to assess changes in every group before and after the treatment. The Mann-Whitney U Test $(\mathrm{p}<0.05)$ was performed to determine the statistical significance of changes between groups after the course of treatment.

\section{Results}

Before the intervention, all groups were equivalent. There were no statistical differences between the intervention group and both of the control groups on neurological, cognitive, affective, and functional scales (Kruskal-Wallis, p>0.05). After the training period, in the intervention group, statistically significant improvements on every cognitive scale were found: MoCA (+27\%), FAB (+18\%), MMSE $(+13 \%)$, clock drawing test $(+27 \%)$, and Shulte's tables $(-21 \%)$ (Table 1$)$. In the active control group, after the patients played entertaining games, no relevant changes on the MMSE and CDT were observed (Wilcoxon Matched Pairs Test, $\mathrm{p}>0.05$ ). However, relevant improvements on the FAB $(+23 \%)$, MoCA $(+16 \%)$, and Shulte's tables $(-32 \%)$ were revealed (Table 2$)$. No statistically significant changes on cognitive scales after observation period were found in the passive control group (Table 3 ).

Table 1. Differences in cognitive parameters in the intervention group (Me [Q1; Q3])

\begin{tabular}{|c|c|c|c|c|c|c|c|c|c|}
\hline & MMSE & FAB & MoCA & $\begin{array}{c}\text { Clock } \\
\text { drawing } \\
\text { test }\end{array}$ & $\begin{array}{c}\text { Shulte's } \\
\text { test }\end{array}$ & $\begin{array}{c}\text { HADS } \\
\text { A }\end{array}$ & $\begin{array}{c}\text { HADS } \\
\text { D }\end{array}$ & NIHSS & IADL \\
\hline $\begin{array}{l}\text { Interven- } \\
\text { tion group } \\
\text { before } \\
\text { treatment }\end{array}$ & $\begin{array}{c}25 \\
{[20 ; 28]}\end{array}$ & $\begin{array}{c}13.6 \\
{[12 ; 16]}\end{array}$ & $\begin{array}{c}20.6 \\
{[18 ; 24]}\end{array}$ & $\begin{array}{c}7.4 \\
{[5 ; 9]}\end{array}$ & $\begin{array}{c}76.5 \\
{[52 ; 103]}\end{array}$ & $\begin{array}{c}3.2 \\
{[1 ; 5]}\end{array}$ & $\begin{array}{c}2.3 \\
{[1 ; 4]}\end{array}$ & $\begin{array}{c}4.6 \\
{[1 ; 10]}\end{array}$ & $\begin{array}{c}16.3 \\
{[10 ; 18]}\end{array}$ \\
\hline $\begin{array}{l}\text { Interven- } \\
\text { tion group } \\
\text { after treat- } \\
\text { ment }\end{array}$ & $\begin{array}{c}28.2 \\
{[26 ; 30]}\end{array}$ & $\begin{array}{c}16.1 \\
{[12 ; 18]}\end{array}$ & $\begin{array}{c}26.1 \\
{[24 ; 28]}\end{array}$ & $\begin{array}{c}9.4 \\
{[8 ; 10]}\end{array}$ & $\begin{array}{c}60.2 \\
{[48 ; 81]}\end{array}$ & $\begin{array}{c}2.5 \\
{[0 ; 4]}\end{array}$ & $\begin{array}{c}2.2 \\
{[1 ; 4]}\end{array}$ & $\begin{array}{c}3.8 \\
{[1 ; 9]}\end{array}$ & $\begin{array}{c}17.1 \\
{[10 ; 20]}\end{array}$ \\
\hline $\begin{array}{l}\text { Changes } \\
\text { (points) }\end{array}$ & +3.2 & +2.5 & +5.5 & +2 & -16.3 & -0.7 & -0.1 & -0.8 & +0.8 \\
\hline $\begin{array}{l}\text { Changes } \\
\text { (percent) }\end{array}$ & $+13 \%$ & $+18 \%$ & $+27 \%$ & $+27 \%$ & $-21 \%$ & $-22 \%$ & $-4 \%$ & $-17 \%$ & $+5 \%$ \\
\hline $\begin{array}{l}\text { Wilcoxon } \\
\text { Matched } \\
\text { Pairs Test }\end{array}$ & $0.004^{*}$ & $0.003^{*}$ & $0.003^{*}$ & $0.004^{\star}$ & $0.003^{\star}$ & $0.013^{*}$ & 1.000 & $0.013^{\star}$ & 0.074 \\
\hline
\end{tabular}

Note. ${ }^{*}=$ statistically significant, Wilcoxon Matched Pairs Test, $\mathrm{p}<0.05$ 
Table 2. Differences in cognitive parameters in the active control group (Me [Q1; Q3])

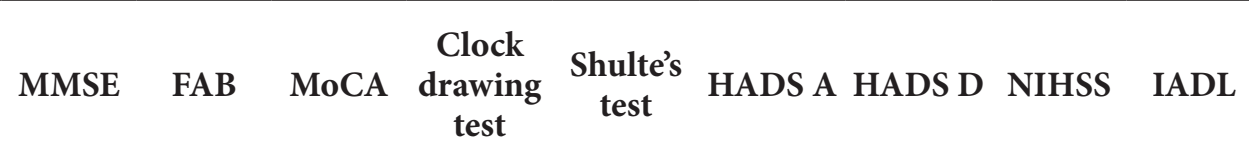

\begin{tabular}{|c|c|c|c|c|c|c|c|c|c|}
\hline $\begin{array}{l}\text { Active } \\
\text { control } \\
\text { group } \\
\text { before } \\
\text { treatment }\end{array}$ & $\begin{array}{c}26.4 \\
{[24 ; 27]}\end{array}$ & $\begin{array}{c}12.1 \\
{[6 ; 17]}\end{array}$ & $\begin{array}{c}21 \\
{[19 ; 24]}\end{array}$ & $\begin{array}{c}7.7 \\
{[5 ; 9]}\end{array}$ & $\begin{array}{c}79.3 \\
{[35 ; 150]}\end{array}$ & $\begin{array}{c}7.3 \\
{[2 ; 18]}\end{array}$ & $\begin{array}{c}6 \\
{[2 ; 8]}\end{array}$ & $\begin{array}{c}4.4 \\
{[3 ; 7]}\end{array}$ & $\begin{array}{c}19.1 \\
{[15 ; 22]}\end{array}$ \\
\hline $\begin{array}{l}\text { Active } \\
\text { control } \\
\text { group after } \\
\text { treatment }\end{array}$ & $\begin{array}{c}27.6 \\
{[25 ; 30]}\end{array}$ & $\begin{array}{c}14.9 \\
{[12 ; 18]}\end{array}$ & $\begin{array}{c}24.4 \\
{[23 ; 27]}\end{array}$ & $\begin{array}{c}8.3 \\
{[5 ; 10]}\end{array}$ & $\begin{array}{c}53.9 \\
{[32 ; 75]}\end{array}$ & $\begin{array}{c}4.1 \\
{[3 ; 10]}\end{array}$ & $\begin{array}{c}4.5 \\
{[1 ; 6]}\end{array}$ & $\begin{array}{c}4.4 \\
{[3 ; 7]}\end{array}$ & $\begin{array}{c}19.4 \\
{[14 ; 22]}\end{array}$ \\
\hline $\begin{array}{l}\text { Changes } \\
\text { (points) }\end{array}$ & +1.1 & +2.7 & +3.4 & +0.6 & -25.4 & -3.2 & -2 & 0 & +0.3 \\
\hline $\begin{array}{l}\text { Changes } \\
\text { (percent) }\end{array}$ & $+5 \%$ & $+23 \%$ & $+16 \%$ & $+8 \%$ & $-32 \%$ & $-44 \%$ & $-25 \%$ & 0 & $+2 \%$ \\
\hline $\begin{array}{l}\text { Wilcoxon } \\
\text { Matched } \\
\text { Pairs Test }\end{array}$ & 0.138 & $0.018^{\star}$ & $0.035^{\star}$ & 0.612 & $0.028^{\star}$ & 0.093 & $0.043^{\star}$ & 1.000 & 1.000 \\
\hline
\end{tabular}

Note. ${ }^{*}=$ statistically significant, Wilcoxon Matched Pairs Test, $\mathrm{p}<0.05$.

Table 3. Differences in cognitive parameters in the passive control group (Me [Q1; Q3])

\begin{tabular}{|c|c|c|c|c|c|c|c|c|c|}
\hline & MMSE & FAB & MoCA & $\begin{array}{c}\text { Clock } \\
\text { drawing } \\
\text { test }\end{array}$ & $\begin{array}{c}\text { Shulte's } \\
\text { test }\end{array}$ & HADS A & HADS D & NIHSS & IADL \\
\hline $\begin{array}{l}\text { Passive } \\
\text { control } \\
\text { group } \\
\text { before } \\
\text { treatment }\end{array}$ & $\begin{array}{c}25.8 \\
{[21 ; 28]}\end{array}$ & $\begin{array}{c}11.9 \\
{[5 ; 16]}\end{array}$ & $\begin{array}{c}20.2 \\
{[15 ; 24]}\end{array}$ & $\begin{array}{c}8 \\
{[5 ; 10]}\end{array}$ & $\begin{array}{c}73.7 \\
{[48 ; 101]}\end{array}$ & $\begin{array}{c}3.7 \\
{[0 ; 10]}\end{array}$ & $\begin{array}{c}3.3 \\
{[1 ; 8]}\end{array}$ & $\begin{array}{c}4.4 \\
{[1 ; 7]}\end{array}$ & $\begin{array}{c}16.8 \\
{[10 ; 24]}\end{array}$ \\
\hline $\begin{array}{l}\text { Passive } \\
\text { control } \\
\text { group after } \\
\text { treatment }\end{array}$ & $\begin{array}{c}26.6 \\
{[22 ; 30]}\end{array}$ & $\begin{array}{c}13.8 \\
{[9 ; 17]}\end{array}$ & $\begin{array}{c}21.3 \\
{[14 ; 27]}\end{array}$ & $8.1[7 ; 10]$ & $\begin{array}{c}80.9 \\
{[44 ; 141]}\end{array}$ & $\begin{array}{c}3.6 \\
{[0 ; 9]}\end{array}$ & $\begin{array}{c}3 \\
{[1 ; 7]}\end{array}$ & $\begin{array}{c}3.7 \\
{[1 ; 6]}\end{array}$ & $\begin{array}{c}17.1 \\
{[10 ; 24]}\end{array}$ \\
\hline $\begin{array}{l}\text { Changes } \\
\text { (points) }\end{array}$ & +0.8 & +1.9 & +1.1 & +0.1 & +7.2 & -0.1 & -0.3 & -0.7 & +0.3 \\
\hline $\begin{array}{l}\text { Changes } \\
\text { (percent) }\end{array}$ & $+3 \%$ & $+16 \%$ & $+5 \%$ & $+1 \%$ & $+10 \%$ & $-3 \%$ & $-9 \%$ & $-16 \%$ & $+2 \%$ \\
\hline $\begin{array}{l}\text { Wilcoxon } \\
\text { Matched } \\
\text { Pairs Test }\end{array}$ & 0.176 & 0.091 & 0.214 & 1.000 & 0.813 & 0.500 & 0.401 & $0.028^{*}$ & 0.480 \\
\hline
\end{tabular}

Note. ${ }^{*}=$ statistically significant, Wilcoxon Matched Pairs Test, $\mathrm{p}<0.05$. 
Paired comparisons of the groups after their treatment courses showed statistically relevant differences between the intervention group and the passive control group on a few cognitive scales: FAB $(\mathrm{p}=0.01)$, MoCA $(\mathrm{p}=0.0004)$, and CDT $(p=0.001)$. No significant changes were found between the group where patients played entertaining games and the group where patients did not receive cognitive training. Also, after the training period was concluded, no statistically significant changes between the intervention group and the active control group were observed (Figure 3).

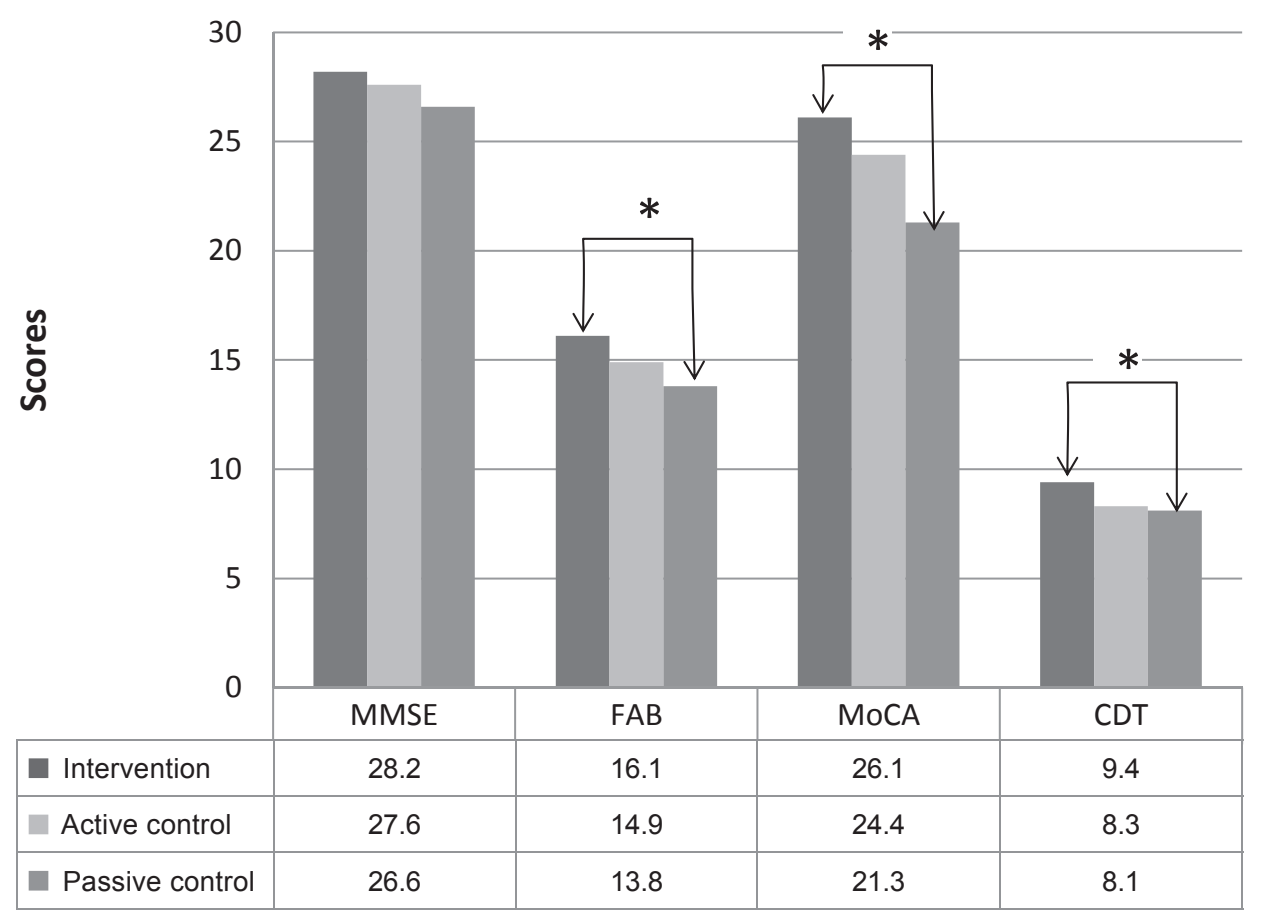

Figure 3. Comparison of cognitive scale results between all groups after the training period

Note. Changes are significant on the FAB, MoCA, CDT, between the intervention and the passive control group (Median, ${ }^{*}=$ statistically significant, Mann-Whitney U Test, $\mathrm{p}<0.05)$.

No relevant changes on the anxiety subscale were found between groups after the training period. After treatment, there was no statistical difference in the neurological state between groups, according to NIHSS.

Changes on the cognitive scales did not influence patients' functional state. The IADL score increased insignificantly in every study group before and after the training, and the difference between groups was not relevant (Mann-Whitney $\mathrm{U}$ Test, $\mathrm{p}>0.05)$.

Neither patients nor clinicians noticed changes in the passive control group, according to the Global Impression scale. There were improvements on the clinicians' global impression scale in both the groups where participants received cognitive rehabilitation, as compared with the passive control group. However, participants who played entertaining games got more satisfaction. 


\section{Discussion}

Computer cognitive training using the authors' neuropsychological computer programs once again has shown effectiveness in the correction of cognitive impairments in the early recovery period of hemispheric ischemic stroke, compared with a similar group where patients did not receive cognitive rehabilitation (Prokopenko et al, 2013; Prokopenko, et al., 2012). A few mechanisms can have an impact on cognitive improvements after cognitive computer training. The first is the activation of median deep subcortical brain structures, which are considered block one of the brain, according to Luria (1962). Nonspecific stimulation can improve involuntary memory, attention, and neurodynamical parameters. However, physiotherapy can also nonspecifically activate neurodynamic parameters.

At the same time, neuropsychological computer programs include tasks that are targeted toward training different cognitive domains, such as visual gnosis, visual spatial gnosis and memory, voluntary attention, and counting. Thus, they can also influence the blocks two and three of the brain, as identified by Luria (1962). To understand the physio-morphological changes at the base of clinical improvements, it is necessary to use additional para-clinical methods.

No statistically significant improvements were observed in the group where participants played entertaining games compared to the group where the cognitive training was not conducted. Although no relevant differences between the effectiveness of computer neuropsychological programs and entertaining computer games were found, this result indicates that it is possible to find statistically significant differences between the intervention group and the active control group if we expand the study groups. It has to be noted that using entertaining games activated patients' attention, sped up their reaction time, improved their visual and spatial orientation, and memory. It can be assumed that any nonspecific cognitive stimulation is effective for cognitive correction during the early recovery period of stroke. An estimation of the long-term effects, and a more detailed analysis of single cognitive domains after using different cognitive methods, are needed in the future studies.

Obviously, the participants who played entertaining games obtained more enjoyment from the treatment due to the more colorful and bright designs of these games. At the same time, the improvements of cognitive state in this group were insignificant compared to other groups. A possible explanation is that PGIS is a subjective scale. They enjoyed the game process; it was fun and fascinating, but not so effective objectively.

The complicated interaction between cognitive decline and depression is well known (Limampai, Wongsrithep, \& Kuptniratsaikul, 2017; Hackett \& Anderson, 2005). After stroke, approximately 30\% of patients experience depression and $20 \%$ anxiety (Hackett, Yapa, Parag, \& Anderson, 2005; Knapp et al., 2017). Individuals with post-stroke depression have a worse functional outcome, slower recovery, and increased mortality (Bartoli et al., 2013). It is also of interest whether anxiety and depression affect the effectiveness of computer cognitive training. In this study, participants differed widely in their emotional states, but it was impossible to analyze subgroups due to the small sample size. This can become the subject of a future investigation. 
Improvements on cognitive scales did not influence the patients' functional states, as shown in most of the studies targeted towards the evaluation of cognitive training (Zucchella et al., 2014; Cicerone et al., 2011). This result can be explained by the short period of observation. Given the fact that all patients had physiotherapy and improved in neurological status, improvements in functional state were expected. It can be assumed that the changes in both cognitive and neurological states were not enough to influence daily living activities, and results should probably be estimated after a few sequence courses. Effectiveness can probably be increased after adapting the studies' regimen.

For future studies, it would be interesting to compare the effectiveness of the computer cognitive training with the conventional neuropsychological rehabilitation course that is usually performed by a neuropsychologist. An investigation of the neuropsychological syndromes and domains which can be restored using computer or conventional approaches, can improve routine clinical practice (Bogdanova, Yee, Ho, \& Cicerone, 2016).

\section{Conclusions}

Thus we have determined that improvements in the cognitive state of patients with post-stroke cognitive impairments were more likely to occur in the group of the computer-based training with special neuropsychological programs, as compared to the conventional treatment.

We also found that the results which followed the stroke patients' playing of entertaining games were statistically insignificant, compared with those receiving only conventional treatment.

It still needs to be clarified as to whether there is a difference between the effectiveness of neuropsychological computer training and entertaining computer games. This question can probably be answered by studies which expand the size of the study groups, and which evaluate the long-term effects of the rehabilitation process.

\section{Limitations}

In this study there were several limitations: a small sample size, a short observation period, and a lack of follow-up examination.

\section{References}

Bartoli, F., Lillia, N., Lax, A., Crocamo, C., Mantero, V., Carra, G. ..., \& Clerici, M. (2013). Depression after stroke and risk of mortality: a systematic review and meta-analysis. Stroke Res Treat, 2013, 11 pages. https://doi.org/10.1155/2013/862978

Bogdanova, Y., Yee, M.K., Ho, V., \& Cicerone, K.D. (2016). Computerized Cognitive Rehabilitation of Attention and Executive Function in Acquired Brain Injury: A Systematic Review. Journal Head Trauma Rehabil, 31(6), 419-433. https://doi.org/10.1097/HTR.0000000000000203

Cicerone, K.D., Langenbahn, D.M., Braden, C., Malec, J.F., Kalmar, K., Fraas, M., ... \& Ashman, T. (2011). Evidence-based cognitive rehabilitation: Updated review of the literature from 2003 through 2008. Archives of Physical Medicine and Rehabilitation. https://doi. org/10.1016/j.apmr.2010.11.015 
Cumming, T.B., Brodtmann, A., Darby, D., \& Bernhardt, J. (2014). The importance of cognition to quality of life after stroke. Journal of Psychosomatic Research, 77(5). https://doi. org/10.1016/j.jpsychores.2014.08.009

Feigin, V.L., Forouzanfar, M.H., Krishnamurthi, R., Mensah, G.A., Connor, M., Bennett, D.A. ..., \& Naghavi, M. (2014). Global and regional burden of stroke during 1990-2010: Findings from the Global Burden of Disease Study 2010. The Lancet, 383(9913), 245-255. https://doi. org/10.1016/S0140-6736(13)61953-4

Feigin, V.L., Lawes, C.M., Bennett, D.A., Barker-Collo, S.L., \& Parag, V. (2009). Worldwide stroke incidence and early case fatality reported in 56 population-based studies: a systematic review. The Lancet Neurology, 8(4), 355-369. https://doi.org/10.1016/S1474-4422(09)70025-0

Finn, M. \& McDonald, S. (2011). Computerised cognitive training for older persons with mild cognitive impairment: A pilot study using a randomised controlled trial design. Brain Impairment, 12(3), 187-199. https://doi.org/10.1375/brim.12.3.187

Gottesman, R.F. \& Hillis, A.E. (2010). Predictors and assessment of cognitive dysfunction resulting from ischaemic stroke, 9(9), 895-905. https://doi.org/10.1016/S1474-4422(10)70164-2

Grigoreva, V., Kovyazina, M., \& Thostov, As. (2012). Cognitive rehabilitation patients with stroke and traumatic brain injury. Nizhni Novgorod State Medical Academy Publishers.

Hackett, M.L. \& Anderson, C.S. (2005). Predictors of depression after stroke: A systematic review of observational studies. Stroke, 36(10), 2296-2301. https://doi.org/10.1161/01. STR.0000183622.75135.a4

Hackett, M.L., Yapa, C., Parag, V., \& Anderson, C.S. (2005). Frequency of depression after stroke: A systematic review of observational studies. Stroke, 36(6), 1330-1340. https://doi. org/10.1161/01.STR.0000165928.19135.35

Hardy, J.L., Drescher, D., Sarkar, K., Kellett, G., \& Scanlon, M. (2011). Enhancing visual attention and working memory with a web-based cognitive training program. Mensa Research Journal, 42(2), 13-20.

Hénon, H., Durieu, I., Guerouaou, D., Lebert, F., Pasquier, F., \& Leys, D. (2001). Poststroke dementia. Incidence and relationship to prestroke cognitive decline. https://doi.org/10.1212/ WNL.57.7.1216

Klochikhina, O.A. \& Stakhovskaya, L.V. (2014). An analysis of epidemiological indices of stroke based on the data of a regional population register from 2009 to 2012. Zhurnal Nevrologii I Psikhiatrii Imeni S.S. Korsakova, 114(6), 63-69.

Knapp, P., Campbell Burton, C., Holmes, J., Murray, J., Gillespie, D., Lightbody, C. ..., \& Lewis, S. (2017). Interventions for treating anxiety after stroke (Review). Cochrane Database of Systematic Reviews, (5). https://doi.org/10.1002/14651858.CD008860.pub3

Lees, R., Fearon, P., Harrison, J. K., Broomfield, N. M., \& Quinn, T. J. (2012). Cognitive and mood assessment in stroke research: Focused review of contemporary studies. Stroke, 43(6), 1678-1680. https://doi.org/10.1161/STROKEAHA.112.653303

Limampai, P., Wongsrithep, W., \& Kuptniratsaikul, V. (2017). Depression after stroke at 12month follow-up: A multicenter study. International Journal of Neuroscience, 7454(January), 1-20. https://doi.org/10.1080/00207454.2016.1277344

Luria, A.R. (1962). Higher cortical functions in man and their disturbances in local brain lesions. Moscow University Press. https://doi.org/10.1007/978-1-4615-8579-4

Miller, K.J., Dye, R., Kim, J., Jennings, J., O’Toole, E., Wong, J., \& Siddarth, P. (2013). Effect of a Computerized Brain Exercise Program on Cognitive Performance in Older Adults. 21:7, Am JGeriatr Psychiatry, 21(7), 655-663.

Narasimhalu, K., Ang, S., De Silva, D.A., Wong, M.C., Chang, H.M., Chia, K.S. ..., Chen, C.P. (2011). The prognostic effects of post-stroke cognitive impairment on dementia and do- 
main-specific cognitive impairments in nondisabled ischemic stroke patients. Stroke, 42(4), 883-888. https://doi.org/10.1161/STROKEAHA.110.594671

Pendlebury, S.T. \& Rothwell, P.M. (2009). Prevalence, incidence, and factors associated with pre-stroke and post-stroke dementia: a systematic review and meta-analysis. The Lancet Neurology, 8(11), 1006-1018. https://doi.org/10.1016/S1474-4422(09)70236-4

Poulin, V., Korner-Bitensky, N., \& Dawson, D.R. (2013). Stroke-specific executive function assessment: A literature review of performance-based tools. Australian Occupational Therapy Journal, 60(1), 3-19. https://doi.org/10.1111/1440-1630.12024

Prokopenko, S.V., Mozheyko, E.Y., Levin, O.S., Koryagina, T.D., Chernykh, T.V., \& Berezovskaya, M.A. (2012). Cognitive disorders and its correction in the acute period of ischemic stroke. Zhurnal Nevrologii I Psikhiatrii Im. S.S. Korsakova, 8(2), 35-39.

Prokopenko, S.V., Mozheyko, E.Y., Petrova, M.M., Koryagina, T.D., Kaskaeva, D.S., Chernykh, T.V. ..., \& Bezdenezhnih, A.F. (2013). Correction of post-stroke cognitive impairments using computer programs. Journal of the Neurological Sciences, 325(1-2), 148-153. https://doi. org/10.1016/j.jns.2012.12.024

Stakhovskaya, L.V., Klochikhina, O.A., Bogatyreva, M.D., \& Kovalenko, V.V. (2013). Epidemiology of stroke in the Russian Federation: results of territory's population registry (20092010). Zhurnal Nevrologii I Psikhiatrii Imeni S.S. Korsakova, 5, 4-10.

Sternberg, D.A., Ballard, K., Hardy, J.L., Katz, B., Doraiswamy, P.M., \& Scanlon, M. (2013). The largest human cognitive performance dataset reveals insights into the effects of lifestyle factors and aging. Frontiers in Human Neuroscience, 7(June), 1-10. https://doi.org/10.3389/ fnhum.2013.00292

Van de Ven, R.M., Murre, J.M., Veltman, D.J., \& Schmand, B.A. (2016). Computer-Based Cognitive Training for Executive Functions after Stroke: A Systematic Review. Frontiers in Human Neuroscience, 10(April), Article 150. https://doi.org/10.3389/fnhum.2016.00150

Xu, X.-D., Ren, H.-Y., Prakash, R., Vijayadas, \& Kumar, R. (2013). Outcomes of neuropsychological interventions of stroke. Annals of Indian Academy of Neurology, 16(3), 319-28. https:// doi.org/10.4103/0972-2327.116909

Zucchella, C., Capone, A., Codella, V., Vecchione, C., Buccino, G., Sandrini, G. ..., \& Bartolo, M. (2014). Assessing and restoring cognitive functions early after stroke. Functional Neurology, 29(4), 255-262. https://doi.org/10.11138/FNeur/2014.29.4.255

Original manuscript received October 1, 2017 Revised manuscript accepted January 17, 2018

First published online June 30, 2018 